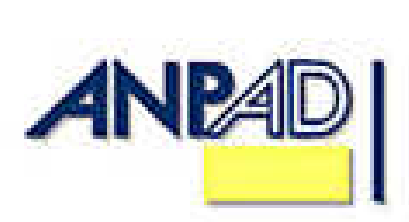

Available online at

http://www.anpad.org.br/bar

BAR, Curitiba, v. 6, n. 3, art. 4,

p. 230-246, July/Sept. 2009

\title{
Trust within Brazilian New Economy Organizations: an Empirical Investigation of Gender Effects Benchmarked on Brazilian Old Economy Organizations
}

\author{
Marco Tulio Zanini * \\ E-mail address: marcotulio@fdc.org.br \\ Fundação Dom Cabral \\ Nova Lima, MG, Brazil. \\ Edward J. Lusk \\ E-mail address: luskej@plattsburgh.edu \\ State University of New York - SUNY \\ New York, USA.

\section{Birgitta Wolff} \\ E-mail address: birgitta.wolff@ww.uni-magdeburg.de \\ Otto-von-Guericke University \\ Magdeburg, Germany.
}

\begin{abstract}
It has been suggested that one of the negative aspects of the New Economy has been growing organizational survival-risk both at the firm and the sector levels. This precarious positioning of the firm has profoundly changed the work environment resulting in the dissolution of job-definition-boundaries, thereby raising the intensity of work and finally affecting the level and nature of trust in the workplace. This is the starting point for our study. Using a questionnaire developed by Gillespie, we investigated gender profiles concerning trust in Supervisors, Peers, and Team in the New and the Old Economies for Brazilian managers. The results show that, for the New Economy, Brazilian women are more willing to give trust to Supervisors whereas Brazilian men expressed higher levels of trust when dealing with Team members. The Peer results are mixed. For the Old Economy, men uniformly express higher levels of trust compared to women over all three reference groups. Finally, for gender matched comparisons, those working in the Brazilian Old Economy firms express higher levels of trust compared to their counterparts in the New Economy independent of gender or time worked. We conclude by discussing the control implications of the above results.
\end{abstract}

Key words: organizational trust; gender; new economy.

Copyright (C) 2009 Brazilian Administration Review. All rights reserved, including rights for translation. Parts of this work may be quoted without prior knowledge on the condition that the source is identified.

* Corresponding author: Marco Tulio Zanini

Avenida Princesa Diana, 760, Alphaville, Lagoa dos Ingleses, Nova Lima, MG, 34000-000, Brazil. 


\section{INTRODUCTION}

Ripperger (1998, p. 45) offers the following definition of trust:

Trust is the voluntary risk investment in advance, in a relationship under the abdication of explicit safeguard mechanisms of control against opportunistic behavior, in the expectation that the other party, despite of the absence of such safeguards, will not behave opportunistically.

This definition is the one that we will adopt for our investigation because, in this conceptualization, control is contingent on trust and trust, as we will argue, is in turn affected by uncertainty. One can imagine, as Ripperger (1998) and Ring and Van de Ven (1994) suggest, that when high levels of trust characterise interpersonal interactions throughout the organization, then the level of control needed through monitoring and the nature of sanctions for dysfunctional opportunistic behaviour will be lower and less severe respectively. The logic of their argument is that the existence of trust within the organization considerably expands the possibility for individuals to form positive cooperative relationships that mitigate against the opportunistic collusive behaviours that often compromise the charge that the organization comply with the laws and regulations relevant in its commercial milieu (Bodnar \& Hopwood, 2004, p. 8).

Williamson (1975, p. 45) argues that trust is also affected by uncertainty. He asserts that uncertainty leads naturally to unpredictability and thus makes opportunism difficult to control because firms would find it difficult to write employment contracts in which all of the dynamic contingencies are specified. Therefore, in the presence of such uncertainty, one expects that the level of trust will be lower and, consequently, requires a higher level of monitoring to control the anticipated opportunistic behaviour.

The plan of this study, therefore, is to see if there are trust differentials that are gender related; if this is the case then one may anticipate or assume that the organization may be at risk for opportunistic behaviour contingent on gender. This risk exposure would then rationalize the commitment of resources to monitor those situations where one anticipates more exposure. How such monitoring should take place is of course another issue. We are only addressing the gender-trust issue and suggesting, depending on the findings, the control implications given the possibility of differential exposure which is dependent on gender. With this baseline definitional information, let us now examine the economic sector labelled as the New Economy in order to set the context for our gender study of trust.

\section{The NeW ECONOMY AND OUR BENCHMARK: THE Old ECONOMY}

According to the International Labour Office [ILO], the Organisation for Economic Co-Operation and Development [OECD] (ILO, 1998, 2001, 2002; Standing, 1997), Perrons (2002) and Perrons, Fagan, McDowell, Ray and Ward (2006, p. 2), the information and telecommunication industries, hereafter ITC, have been labelled as principal members in the sector now called the New Economy, principally due to their high levels of market uncertainty and their organizational instability. According to the ILO and the OECD, in the ITC sector, market uncertainties are relatively high due to: (1) globalisation, (2) the rapid development of new products thus dramatically shortening the obsolesce cycle, (3) the establishment of companies financed by short-term venture capital funding, (4) the ongoing and often misguided process of regulation in particular the Sarbanes-Oxley Act of 2002, (Lusk, Schmidt, \& Halperin, 2006), and (5) failures in demand forecasts. Fransman (2002, p. 33) notes that "mistakes are an inevitable consequence of the irreducible uncertainty which always shrouds complex events such as those which occurred in the Telecom Industry in the Internet Age". 
These factors have precipitated changes in the nature of work in companies of the ITC sector. For example, Burton-Jones (1999) and Neumark and Reed (2002), considering the work conditions in the New Economy, observe that volatility and the shortened tenure of employment contracts have adversely impacted trust relationships. Burton-Jones comments: "employers and employees will be increasingly wary of entering into agreements which contain implicit guarantees or promises". Consistent with Williamson (1975), Burton-Jones (1999, p. 53) further offers that

this lack of mutual trust caused by such uncertainty will continue to weaken the value of the employment contract as a form of work arrangement and move the employment relationship away from its relational context towards a more explicit transactional model.

In a similar vein, according to Audretsch and Thurik (2001, p. 15), the degree of uncertainty and turnover experienced by workers in the New Economy is a window to the great turbulence and instability of the firms in this sector. Replacing long-term fixed contracts with new flexible forms of contingent work contracts provides the essential vehicle driving the transition from the Old Economy to the New Economy resulting in increasing levels of uncertainty. Furthermore, Argandona (2003, p. 17) suggests that this characteristic of the New Economy, combined with other environmental elements, has radically changed the work conditions towards more conflicts in the work environment, higher internal cut-throat competition and disintegration of loyalty; they have also encouraged opportunistic and unethical behaviour. Argandona observes that the New Economy firms are usually companies with a younger workforce and are marked by high employee turnover due to the constant re-dimensioning of the workforce through layoffs and outsourcing. Concerning the Old Economy, Argandona (2003) and Burton-Jones (1999) characterize the Old Economy, in comparison to the ITC sector, as a sector of firms whose workers have long-term labor contracts and show more loyalty and attachment to the company-i.e., by most measures, the polar-extreme to the New Economy. This is the reason that we have decided to benchmark our gender study of the New Economy using the firms sampled from the Old Economy. It is also interesting to note that, based upon a comprehensive ABI and Business Source Premier databases search, last effected 8 September 2008, there were no articles retrieved that reported on sampled gender-trust issues from New Economy firms. Therefore, our study is the first to provide such information. Consider now the study design by which we will address the question of gender and trust in the New Economy.

\section{THE Trust StudY}

\section{Study Design and Sample}

To investigate the trust-gender relationships in the New Economy, we surveyed members of six Brazilian firms: three from the ITC sector, and three firms one each from the mining, petrochemical and the steel sectors. We used as the survey instrument, the Behavioural Trust Inventory [BTI] developed by Gillespie (2003).

\section{Criteria for Classification of the Study Organizations}

For sample validation purposes, we blind-classified the six study firms into two groups using two different techniques. First, based upon the similarity of the firms' performance as reported as part of the public information that Brazilian firms are required to publish, we clustered the six firms into two groups; and second, two experienced Brazilian financial analysts were asked to group the six firms into what they believed to be typical firms in the New and Old Economies. For example, regarding the classification by reported performance, we used average employee turnover as one of the performance statistics. The three firms with highest employee turnover ranged from $16.9 \%$ to $39.0 \%$, whereas the range of the firms with the lowest employee turnover was $3.0 \%$ to $4.7 \%$. The firms in the high turnover cluster were the ITC firms, and the firms in the low turnover group were the mining, 
petrochemical and steel firms. By both methods, two groups were produced: the three ITC firms grouped together - we label them as our New Economy sample - and, the mining, petrochemical and steel firms grouped together and labelled as the Old Economy sample. We have thus validated that the firms that we selected from the ITC sector fit the profile of New Economy firms and are different from the firms that best fit the profile of the Old Economy — our benchmark group.

\section{The Survey Instrument}

The selected questionnaire, called the Behavioral Trust Inventory [BTI], was designed by Nicole Gillespie from the Melbourne Business School, University of Melbourne, Australia. The trust scale was specifically designed to assess the willingness to be vulnerable in interpersonal work relationships. The instrument was designed to assess interpersonal trust in the work relationships between leaders and their followers, and among peers. The inventory has also been used to assess leaders' and members' trust towards their work team.

The BTI was specifically designed to assess one's willingness to be vulnerable in interpersonal work relationships; this fits well with Ripperger's definition cited above. There are 30 questions in total, each one measured on a standard Likert scale. The Likert scale labels for all the questions in the BTI are: ' 1 ' is labelled Not at all willing and ' 7 ' is labelled as Completely willing. The first ten questions deal with interpersonal trust between the respondents and their Supervisor, the next ten assess interpersonal trust between the respondent and a particular Peer, and the last ten questions address interpersonal trust between the respondents and their Team. Moreover, the trust scales for each interpersonal associational group are divided into two factor groups. The first five questions for each of the three groups: Supervisor, Peer and Team address trust within specific work-related situations, called the Reliance or Professional dimension; the last five questions per group are designed to measure trust at a personal level, called the Disclosure or Personal dimension. As our survey took place in Brazil, the original BTI English-language questionnaire was translated into Portuguese and that translation was double-blind validated.

Examples of the questions from the two factor groups are Questions 4 [Professional Group] and 9 [Personal Group] for the Supervisor Section of the BTI:

. Question 4: Depend on your manager to back you up in difficult situations.

- Question 9: Discuss with your manager how you honestly feel about your work, even negative feelings and frustration.

In this regard, Gillespie (2003, p. 35) notes, "whilst the first five questions are based on 'professional' forms of trust, on a more calculative basis, related to professional relationships, the last five questions of the scale are based on "personal' forms of trust".

To better understand the nature of the BTI, consider now its developmental details as reported by Gillespie (2003, p. 8). She notes on:

There were two aims in developing the BTI. First, the BTI was designed to measure a person's willingness to be vulnerable in a relationship with a specified other, across multiple domains of trusting behavior. Specifically, the inventory required respondents to indicate their willingness to engage in trusting behaviors with the target person. Second, the BTI was designed to measure trust in leader-member and peer relationships in a team setting. Hence the inventory needed to capture the essential features of these typically complex and highly interdependent work relationships.

To this end, Gillespie used qualitative data, as well as cross-sectional longitudinal matched-dyad quantitative panel data in the development and validation of the BTI. This information was drawn from the following samples: an interview sample of 32 triads resulting in 96 interview assessments, two pilot samples $(n=39$ and $n=24)$ where content validity of the BTI was demonstrated including 
the its discriminate properties, a second validation sample of 88 leader-member dyads and a subsample of that group and finally a sample of 67 mangers and 214 of their direct reports.

Gillespie used a hypothesis testing approach to establish construct validity. This technique examines the responses to the BTI as conditioned on related measure in the nomological network. In Gillespie's study, this addresses the Reliance and the Disclosure dimensions, which are the two factors named by Gillespie from her factor study. This relational validation is a standard technique in organizational studies and was first proposed by the pioneering work of Cronbach and Meehl (1955) and follows the associational relationships as drawn from a specific context. Also see Nunnally (1978). For further information on the development and application of the BTI see, Burke, Sims, Lazzara and Salas (2007), Lewicki, Tomlinson and Gillespie (2006) and Gillespie and Mann (2004).

For our use of the BTI, we computed the Split-Reliability measure of Cronbach, called the Cronbach- $\alpha$. For our factors, addressing Professional and Personal Dimensions separately over the three study groups, Supervisors, Peers and Team, we find the Cronbach- $\alpha$ to be in the range of [0.916 to 0.941 ] and so was never below 0.7, which is the frontier cut-off suggested by Nunnally (1978) for statistical significance.

\section{The Study Sample}

The BTI information was collected from July to October, 2004. The individual return rates are: For the New Economy sample, Firm 1 had a return rate of 63\%, with 233 usable questionnaires, Firm 2 [83\%, $\mathrm{n}=313]$, Firm 3 [72\%, $\mathrm{n}=242]$. For the Old Economy sample, the return rates were: Mining [72\%, $\mathrm{n}=155]$, Petrochemical [80\%, $\mathrm{n}=188]$ and Steelworks [86 \% $\mathrm{n}=302]$. Overall, these sample sizes allow good statistical precision at better than $5 \%$ of the Likert scale range for two sample meanlevel testing with alpha-control of at least $95 \%$ and power of at least $80 \%$.

\section{DEVELOPMENT OF THE HYPOTHESES}

Before we discuss the development of the study hypotheses, two qualifications are needed:

1) We are interested in the managerial relationships for the individuals in their particular institutions; because most of the individuals have people in the system reporting to them, we eliminated from the database those individuals who had no people reporting to them. This was less than one percent of the individuals accrued, and

2) For politically correct reasons relating to the difficulty in asking about the nature of the supervisory relationships in the Brazilian institutional framework as well as the definitional difficulties in drawing supervision boundaries, we did not ask the respondents to indicate their managerial status: senior, middle or junior managers.

\section{The Brazilian Institutional Framework: Our Study Context}

Preliminarily, to get an idea of the distribution of gender for the two institutional frameworks, we categorized gender over the length of employment for the New and the Old Economies. This provides the following two important aspects that we will use in developing the study hypotheses:

1) The overall proportion of men to women for the two institutional frameworks, and

2) The proportional gender distributions within institutional framework over the length of employment.

The results of these categorizations are presented in Tables 1 and 2 following: 
Table 1: The New Economy: Time of Employment by Gender

\begin{tabular}{|l|c|c|c|}
\hline Count & Women & Men & Totals \\
\hline Duration - > y yrs & 24 & 40 & 64 \\
\hline Duration - [4 to7] yrs & 101 & 129 & 230 \\
\hline Duration - < 4 yrs & 200 & 288 & 488 \\
\hline Totals & 325 & 457 & 782 \\
\hline
\end{tabular}

Table 2: Old Economy: Time of Employment by Gender

\begin{tabular}{|l|c|c|c|}
\hline Count & Women & Men & Totals \\
\hline Duration - > 7 yrs & 40 & 347 & 387 \\
\hline Duration - [4 to7] yrs & 8 & 75 & 83 \\
\hline Duration - < 4 yrs & 41 & 133 & 174 \\
\hline Totals & 89 & 555 & 644 \\
\hline
\end{tabular}

Here we find that the gender distribution is relatively balanced for the New Economy compared to that of the Old Economy. For the New Economy, 41.6\% [325/782], are women whilst for the Old Economy the proportion of women is $13.8 \%$ [89/644]. This proportional difference tests as being statistically significant at $\mathrm{p}<0.001$. Furthermore, the overall $\chi^{2}$ of the New Economy gender classification table is not statistically significant, suggesting that there is a proportional distribution of gender over the length of time in the organization. This is not true for the Old Economy, where the $\chi^{2}$ is significant at $\mathrm{p}<0.001$ suggesting that there are a-proportional gender distributions. Using the $\chi^{2}$ contribution per cell (Tamhane \& Dunlop, 2000), we may conclude for the Old Economy that there are more women who have been recently hired and less women in the long-term employment status. These gender distributions may be simply summarized as follows: it appears that the supervisor to supervisee gender match is more balanced in the New Economy compared to that found in the Old Economy. Risking a summary caricature, one may assume that men are supervising women to a greater extent in the Old Economy; while there seems to be a relative balance in terms of supervisory relationships for the New Economy.

\section{The Study Context as viewed through the Literature}

With this preliminary information of the distributions of gender for the two study sectors, let us (1) consider the information from the literature that bears upon the gender issues in the Brazilian institutional framework and (2) examine the historical settings for the New Economy and the Old Economy.

The Literature. Regarding gender wage differences, according to Arabsheibani, Carneiro and Henley (2003) and Arbache and Loureiro (2005), there has been a substantial reduction in gender wage differentials over the last two decades. For instance, Arbache and Loureiro (2005) observe that the legal institutional mechanisms established by the Brazilian Federal Constitution starting in 1988 have now largely eliminated clientelism and male-nepotism, and have created a convergence in the average wage for women and men. In addition, according to the Conselho Nacional dos Direitos da Mulher [CNDM] (National Committee for Women's Rights) (2004), almost 80\% of Brazilian women who work out of the home have their jobs in the service sector; and, at present, the proportion of women in 
jobs requiring a university degree is $51.5 \%$. We also see this reflected in Table 2 , where the newly hired women constitute a higher proportion compared to the women who have been in the Old Economy for a number of years.

The Historical Context:

1) Pre-Feminist. Press (1991) marks the 1940s through the 1950s as a pre-feminist period. This period was characterized by the traditional phallo-centric divisions of labor where men 'go to work' while females 'stay at home' as care-takers and care-givers. This extended then naturally to the distribution of organizational tasks with men engaged in the 'doing of' productive work while women were employed as 'in-house' facilitators playing administrative and secretarial roles. Consequently, the hierarchical relationships and so the supervisory roles have developed under predominantly the traditional feminine/masculine role juxtapositions, where one finds men working out of the house and women working in the house.

2) The 1970s to Privatization. According to Castells (1996) and Audretsch and Thurik (2001), remarkable institutional changes occurred after the transitional period of the 1960s that established two periods respectively, one marked by social stability, in the early 1970s, and the other marked by turbulence, in the late 1970s. In the 1980s, according to Arabsheibani et al. (2003), there was a reduction in discrimination against women in Brazil, resulting in an increase of women entering the labor market and a narrowing of the female wage-gap. However, a factor that seemed to work against the gender-liberalization in evidence in the 1980s was the fact that, from 1964 until 1985, Brazil was governed by a military dictatorship under which five military-tapped presidents served. This military influence reinforced the male-dominated hierarchy already in place in the industrial sector, in particular in those Brazilian industries linked to the military such as: Mining, Petrochemicals and Steel. As Gordon (1991) observes, such industry determinants define patters of behavior that finally shape organizational cultures. A particularly important facet of this influence was the marginalization of women who were not permitted to be in the military chain of command but rather served as secretaries and facilitators, much like their traditional roles in the home. So, on the one hand, there was a loosening of the restrictions on the female presence in the work force but perhaps, in some sectors, their roles did not change and they still were in the roles of facilitators to the men who were in charge.

3) Post-Privatization. According to Tanure (2005), even considering the social pressure of feminism in the 1970s and the sweeping economic changes effected by the privatization of 1998 coupled with the Internet and globalization, the traditional Old Economy companies have retained their male-dominated hierarchy both regarding career pathways and employee retention policies. Consistent with the findings of Fransman (2002), another important aspect of post-privatization is the relative chaos of the dynamic New Economy compared to the Old Economy. The most telling single statistic is the employee turnover information presented above; a further related statistic is the length of time that individuals have remained in their positions. For the New Economy, the average tenure is 3.7 years, compared to the Old Economy's 13 years.

\section{Hypotheses}

Given the literature review, the historical information on the Brazilian commercial milieu and the gender distributions represented in Tables 1 and 2, we offer the following hypotheses that are due principally to the assumed male-dominated traditions in the Old Economy coupled with its relative stability compared to the New Economy, where there is a relative gender-balance and a much higher degree of uncertainty:

H1. Men in the Old Economy will express a higher degree of trust for all three interpersonal associational groups [Supervisors, Peers and Team] over the two factor dimensions [Professional and Personal] compared to women in the Old Economy. 
H2. For the New Economy, there will be no pattern of trust regarding gender for any of the three associational interpersonal groups [Supervisors, Peers and Team] nor for the two factor dimensions [Professional and Personal].

Given that we have now developed two hypotheses for the gender expression within the Old and the New Economies, consider now the relationship between these institutional frameworks:

H3: Controlling for gender, trust in the Old Economy will be uniformly greater than the trust expressed by those in the New Economy independent of the time worked in the organization.

This hypothesis derives from the fact that a more established organizational culture creates a better environment for the socialization of those recently hired into the company (see Robbins, 2002, p. 504). Also, according to Axelrod (1984), Kreps (1990) and Ricketts (2002), patterns of behavior will be better defined and constantly shared by those who have been interacting within the system for a substantial period of time, thus providing the success-signals to newer people in the system. As Kreps's work (1990) suggests, this Role-Model transfer of information seems to be a way that information is passed from generation to generation in the organization through organizational reputation. Furthermore, Robbins (2002, pp. 504-511), suggests that one can expect that the more established and stable organizational cultures will communicate such behavioral cues more effectively, essentially because the new entrants in the system observe that such cooperative trust-oriented behaviors work by definition-i.e., presumably these individuals in the system have remained in the system due to such non-opportunistic behaviors, and so these are the communicated self-fulfillingpathways to success. Finally, Burton-Jones (1999, p. 53) extends this idea and offers that, as trust is related to expectations and attitudes regarding others' future behavior, it is expected then the levels of trust in the Old Economy will be higher compared to those of the New Economy, where, due to the dynamic nature of the New Economy, such clear success criteria that are linked to trust are less likely to develop, thereby promoting more opportunistic behavior. Therefore, because the belief in trust as the characteristic profile in the Old Economy is communicated throughout the organization, as suggested above, trust should be embraced by members of the organization independent of the time that they have spent in the organization. Given that we have now suggested three study hypotheses, let us discuss the test protocols and then present the results of the study.

\section{Testing Protocols}

\section{Testing Protocols for $\mathrm{H} 1$ and $\mathrm{H} 2$}

We will examine the pair-wise gender mean comparisons within the two institutional frameworks: the New Economy and the Old Economy. We will report two-tailed p-values for all of the 60 gender comparisons-i.e., three associational groupings of ten questions each over the two institutional frameworks-to provide information for future meta-analyses. Given Gillespie's questionnaire, we expect, the inter-question correlation to be non-zero, as indeed turns out to be the case. However, even though this association exists, that does not in and of itself indicate that the associated gender means will follow a particular pattern. For purposes of providing test information for $\mathrm{H} 1$ and $\mathrm{H} 2$, we will use the following inference logic: When the results within a factor block are in the majority for either the Female or Male respondents and at least one contrast in that majority grouping is statistically significant or suggestive, we will use that profile in drawing an inference. Within a factor block when this is not the case, then we will use the binomial probability to compute an intra-factor p-value. Conservatively, the success probability will be set at the null of chance and because we are examining mean-level gender differences it is not inconsistent, in this case, to assume that the intra-factor gender mean realizations are independent. For inference purposes, we will assume that p-values less than 0.1 indicate statistical significance. P-values in the range [0.15 to 0.1$]$ will be referred to as suggestive; and $\mathrm{p}$-values greater than 0.15 will be labeled as non-significant. 


\section{Testing Protocol for $\mathrm{H3}$}

We will have the following gender matched contrasts: women who have been in their institutional framework for a Short period of time-less than four years. The same contrast will be made for the men. At the other end of the spectrum, we will make the same gender contrasts over the two sectors for those who have been in their organizations for a Long period of time-in this case more than seven years. We have eliminated the transitional group, those who have been with the organization four years or more but seven years or less. This will help to focus the analysis on the relative polar extremes and so better examine the length-of-time effect. To be clear, we have the following set of contrasts:

1) Women, with less than four years in the New Economy contrasted with their female counterparts in the Old Economy: Note this grouping as [WSN vs. WSO]

2) Women, with more than seven years in the New Economy contrasted with their female counterparts in the Old Economy: Note this grouping as [ $W L N$ vs. $W L O]$.

3) Men, with less than four years in the New Economy contrasted with their male counterparts in the Old Economy: Note this grouping as [MSN vs. MSO].

4) Men, with more than seven years in the New Economy contrasted with their male counterparts in the Old Economy: Note this grouping as [MLN vs. $M L O]$.

These contrasts will provide information on the relative level of trust which can be attributed to the institutional framework controlling for time in the organization and examining the resulting gender effects as scripted by H3. Consider now the reduction of the contrast space achieved though factor analysis. This will enable us to economically present the above mentioned four contrasts as adding the length of time dimension doubles the number of contrasts to 120 .

\section{Factor Reduced Variable Space}

We expect that there will be two factors: Reliance for the Professional dimension and Disclosure for the Personal dimension, because that is the way that Gillespie's questionnaire was developed. Specifically, and following the same standard procedures as Gillespie used in the validation of the BTI, we will rotate the correlation matrix using the standard varimax rotation and choose the number of factors based upon the number of eigenvalues not less than 1.0. This is the standard as established by Harmon (1960) and follows the average contribution logic in that the eigenvalues greater than 1.0 contribute more variance explanation in the rotated space than the average if the null were true, in which case each variable would have an eigenvalue of 1.0 Then we will select the candidate descriptor variable from the resultant factors based upon the highest loading that has a value greater than $\sqrt{ } .5$. Here again this is the Harmon-standard, in that such a cut-off guarantees that no variable can exceed that loading in that the sum of the loadings is unity.

Using these protocols, we found for each of the two factors the exact same variable loading configuration as was reported by Gillespie-i.e., Reliance and Disclosure. The p-value for the null of this exact matching is less than 0.0001, which strongly argues for rejecting the null in favor of the replication of Gillespie's two factor structure in our sample. Therefore, in summary, we found the exact same factor configurations as was reported by Gillespie (2003).

\section{A Discussion of our Inference Methodology}

The hypotheses will be tested under a robustness protocol. This is necessary because there were numerous instances where the data did not follow the pattern that would justify the sole use of parametric tests. For example, where there were outliers or a-symmetric distributions, one prefers nonparametric tests. We reported, conservatively, the highest $\mathrm{p}$-value as between the parametric and the 
non-parametric tests when either test could have been used. If the non-parametric test was indicated, we used that test. Specifically, we used the Wilcoxon Rank Sum Test for the ANOVA comparisons and the Wilcoxon Signed Rank Test for testing against a pre-specified value. For Multiple comparison tests, we used either the Tukey-Kramer HSD multiple comparison test [MCT] or the Hettmansperger MCT, depending on the central tendency statistic in question. For the multiple comparison tests, we set the detection- $\alpha$ at 0.10 . To facilitate interpretation of the data and to aid in future Meta-Analyses the two-tailed $p$-values were reported. We bolded and considered for inferential analyses p-values < 0.10 .

\section{Factor/Variable Identification}

For each of the three associational groupings, Supervisors, Peer and Team, we used the ten questions that are the variables by which information is collected for the three associational groups. As expected, for each associational group there were two eigenvalues not less than 1.0. The resulting two factors for each of the three associational groupings had loadings that separated into the two dimensions along the questions as follows: the first dimension was defined by loadings of the first five questions, and the second factor was defined by the second five questions. This is what was expected because this is the factor structure of Gillespie's questionnaire as it was validated. Only in one case for the three associational groups was the factor loading less than $\sqrt{0.5}$-it was 0.70 . All three associational groups had the same variables as the leading loaded variable: The third and the eighth questions respectively. For example, the Team rotated factor matrix produced two factors; for the first factor, Questions T1, T2, T3, T4 and T5 all had loadings in excess of $\sqrt{0.5}$, thus confirming the dimensional categorization expected. For these five questions, the variable loading for the third question, T3, was the largest in absolute value. For this reason, we selected for the Team associational group Question 3 as the representative expression of the professional dimension. For the second factor, for the Team associational grouping, Question 8 from the five questions: Questions T6, T7, T8, T9 and T10 had the highest loading. This same result was also obtained the Supervisory and the Peer associational groups. Therefore, as the variables for the three associational groups, we selected for each the following two questions:

Reliance. Questions S3, P3, T3: Rely on your [manager/peer/team member] to represent your work accurately to others.

Disclosure. Questions S8, P8, T8: Confide in your [manager/peer/team member] about personal issues that are affecting your work.

These six questions, as factor representations from their respective dimensional grouping, are those with which we will examine the following four contrasts:

1) WSN contrasted with WSO

2) WLN contrasted with WLO

3) MSN contrasted with MSO

4) MLN contrasted with MLO

Now we will present the results of the study that provide information on the three study hypotheses.

\section{Results}

Results for $\mathrm{H} 1$ and $\mathrm{H} 2$ : The results are presented in Tables $3 \mathrm{a}, 3 \mathrm{~b}$ and $3 \mathrm{c}$ below. Each table gives the gender group, Women (W) or Men (M), which expressed the highest level of trust as measured by the mean value followed by the two-tailed $\mathrm{p}$-value. We will summarize the results for each table 
individually and then give an overall summary relative to $\mathrm{H} 1$ and $\mathrm{H} 2$. The two-tailed p-values less than 0.1 have been bolded.

Table 3a: Trust Expressed for the Supervisor Associational Grouping

\begin{tabular}{|l|l|l|l|l|l|l|l|l|l|l|}
\hline Qs & S1 & S2 & S3 & S4 & S5 & S6 & S7 & S8 & S9 & S10 \\
\hline New & W.0002 & W.29 & W.009 & W.23 & W.30 & W.68 & W.14 & W.71 & W.65 & W.46 \\
\hline Old & W.25 & W.82 & M.60 & M.42 & M.23 & M.11 & M.03 & M.37 & M.02 & M.22 \\
\hline
\end{tabular}

We should bear in mind that in some cases we are using the binomial probability for purposes of inference. For example, for the New Economy in the disclosure/personal factor block — questions S6 to S10, none of the individual differences were statistically significant but in all five cases the mean values expressed by female respondents were greater than those of the male respondents. In this case, then using the binomial distribution, we compute the p-value for this situation to be 0.0325 . This simply says that for the binary comparison: women compared to Men, the probability of finding five means all in the same direction by chance - i.e., all from the female respondents - would happen rarely, here less than four percent of the time. This then argues for statistical significance, meaning the there is evidence that the women have expressed more trust than their male counterparts for that factor block.

With this inference system, we see the following results for the New and Old Economies:

1) Women in the New Economy, for both the professional and the personal dimensions, express more trust than do their male counterparts respecting their interactions with their supervisors.

2) Men in the Old Economy for the personal dimension express more trust than do their female counterparts respecting their interactions with their supervisors.

3) For the Old Economy, there is a suggestive result for the professional dimension. Remember that for the Old Economy we will be using, for purposes of inference, one-tailed tests due to the fact that $\mathrm{H} 1$ is directional. We find for a majority of the cases, three of five, that the men have expressed relatively more trust and for question 5 [S5] and they have expressed significance at a suggestive level of 0.115 [0.23/2]; and for this reason we note this as a suggestive result since this $\mathrm{p}$-value falls in the suggestive range.

These results indicate that the Brazilian women in the New Economy for both the professional and the personal dimensions have placed more trust in their supervisor than have the Brazilian male respondents. For the Old Economy, the Brazilian men have placed more trust in their supervisors than have their female counterparts but only for the personal dimension. There is a suggestive result for the professional dimension where men in the Old Economy have registered suggestive results.

In this case, for the supervisory aspect, there is overall suggestive support for the Supervisor component of $\mathrm{H} 1$ - which assumes that Brazilian men working in the Old Economy will express a higher degree of trust than will their female counterparts; however, there is no support for $\mathrm{H} 2$ - that there will not be a gender pattern in the New Economy. We see that, for the New Economy, the women have expressed more trust than have their male counterparts over both factor dimensions.

Table 3b: Trust Expressed for the Peer Associational Grouping

\begin{tabular}{|l|l|l|l|l|l|l|l|l|l|l|}
\hline Qs & P1 & P2 & P3 & P4 & P5 & P6 & P7 & P8 & P9 & P10 \\
\hline New & W.32 & M.70 & W.76 & W.59 & W.82 & M.92 & M.42 & M.86 & M.13 & M.84 \\
\hline Old & M.60 & M.62 & M.57 & M.43 & M.39 & M.83 & M.34 & M.79 & M.19 & M.78 \\
\hline
\end{tabular}


For relationships with peers, we find statistical significance for the personal dimension for both the New and Old Economies, where the men uniformly have scored higher than the women. For the professional dimension for the New Economy, the results are not significant and were mixed between the women and men. Finally, for the Old Economy, considering the professional dimension, the Brazilian men have expressed a higher level of trust compared to their female counterparts. Therefore, the Peer component of $\mathrm{H} 1$ as stated is supported. For H2, a male dominated pattern was exhibited in the personal dimension, thus failing to provide support for the no-pattern nature of H2. Only for the professional dimension in the New Economy was there no gender pattern.

Table 3c: Trust Expressed for the Team Associational Grouping

\begin{tabular}{|l|l|l|l|l|l|l|l|l|l|l|}
\hline Qs & T1 & T2 & T3 & T4 & T5 & T6 & T7 & T8 & T9 & T10 \\
\hline New & W.91 & M.03 & M.44 & M.21 & M.03 & M.07 & M.02 & M.01 & M.0002 & M.04 \\
\hline Old & M.08 & M.04 & M.04 & M.01 & M.02 & M.10 & M.07 & M.37 & M.03 & M.05 \\
\hline
\end{tabular}

Here we find, for the New and Old Economy, that the Brazilian men have expressed for their Team associational grouping a higher level trust compared to their female counterparts. This provides support for the Team component of $\mathrm{H} 1$ and a conclusive rejection of $\mathrm{H} 2$.

\section{Summary of the Relationships over the Three Associational Groupings for $\mathrm{H} 1$ and $\mathrm{H} 2$}

The summary profile of these three associational groupings is presented in Table 4. Regarding the encoding of statistical significance in Table 4, if for a factor block (Professional [Pro] or Personal [Per]) the result was statistically significant, then that factor block will be noted in black; where differences were suggestive, then the factor block is gray. If for a factor block there were nonsignificant results, then the factor box is white. For example, consider the results in Table $3 \mathrm{~b}$ for the Peer group. For the New Economy, considering the professional dimension, the result is mixed and using the binomial probability is not statistically significant and so that factor block is white.

Table 4: Graphic Presentation of the Differences on Trust Levels by Gender between the Brazilian New and Old Economies

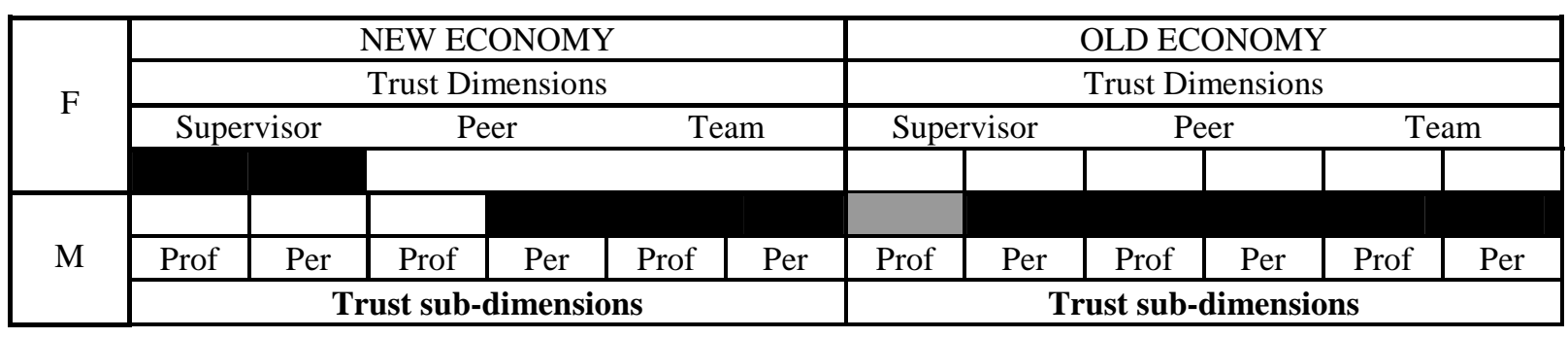

Table 4 illustrates differences in trust by gender between the New Economy and the Old Economy. As a point of reference, if $\mathrm{H} 1$ were to be supported, then all the boxes in the Old Economy for the men would be black; and for $\mathrm{H} 2$, all the boxes for both the women and men would be white.

For Table 4, we observed that trust is a gender sensitive variable in particular between institutional frameworks. For H1, one can see from Table 4, as hypothesized, that for the Old Economy the Brazilian men have uniformly expressed higher levels of trust compared to their female counterparts. Only for the supervisor group for the professional dimension were the results suggestive. For all the other factor blocks the results were statistically significant. For the Old Economy then, these results follow from the presumed male socialization promoted by the influence of the military during the 1980s that created, in resonance with Gordon's (1991) argument on the configuration of industry 
determinants, a military-like male dominated decision making hierarchy. Furthermore, our data show that in the New Economy, contrary to hypothesis $\mathrm{H} 2$ of no pattern, women seem to be more trusting in both professional and personal situations when dealing with supervisory authority; and men feel more comfortable giving trust to members of their team.

\section{Results for $\mathrm{H3}$}

The test results for $\mathrm{H} 3$ are presented in Table 5, where we present the group achieving the highest mean value followed by the corresponding one-tailed p-value. Here we have bolded those results for which the one-tailed p-values are less than 0.1 as they are consistent with $\mathrm{H} 3$, which is directional.

Table 5: Gender and Time Matched Contrast for the New and Old Economy

\begin{tabular}{|c|c|c|c|c|c|c|}
\hline & \multicolumn{2}{|c|}{ Supervisor } & \multicolumn{2}{c|}{ Peer } & \multicolumn{2}{c|}{ Team } \\
\hline & S3 & S8 & P3 & P8 & T3 & T8 \\
\hline WSN or WSO & WSO.39 & WSO.41 & WSO.37 & WSO.18 & WSO.23 & WSO.15 \\
\hline WLN or WLO & WLO.095 & WLO.27 & WLO.01 & WLO.025 & WLO.38 & WLO.10 \\
\hline MSN or MSO & MSO.0015 & MSO<.0001 & MSO.035 & MSO.048 & MSO.28 & MSO.18 \\
\hline MLN or MLO & MLO<.0001 & MLO<.0001 & MLO.06 & MLO.065 & MLO.01 & MLO.0015 \\
\hline
\end{tabular}

For example, for question P8 - i.e., the eighth question in the Peer section of the questionnaire for the Males who had worked a $\underline{S}$ hort time in their organizations, we found that the men in the New Economy [MSN] scored that question so that it had a mean of 4.7; their male counterparts in the Old Economy [MSO] scored P8 so it had a mean of 5.2, indicating a higher level of trust. This difference was statistically significant, with a p-value of less than 0.1 ; in this case a one-tailed p-value of [0.048]. This is then the coding that is noted above as MSO.048 in the intersection of the P8 column and the [MSN or MSO] row.

\section{Discussion of the Results}

For the Brazilian women, the comparisons across the two institutional frameworks using the binomial testing model, here over the 12 realizations, indicate that there is statistically significance evidence that the women in the Old Economy have expressed a higher level of trust than have their counterparts in the New Economy. This result, in that it is found for both duration groups, then holds independent of time spent in the institutional framework. Also using the binomial model, the results for the Brazilian men support $\mathrm{H} 3$ in that the men in the Old Economy also have expressed a higher level of trust compared to their counterparts in the New Economy. In fact, for all 120 comparisons, all of the means for the respondents in the Old Economy are greater than those for their matched counterparts in the New Economy.

These results follow in a definitive way the results of Burton-Jones (1999), Audretsch and Thurik (2001), and Argandona (2003) that the New Economy engenders lower levels of trust due to a lack of stability as clearly indicated by the dramatic difference in the level of employee turnover between the New and Old Economies previously presented. Accordingly, as Burton-Jones (1999, p. 53) suggests, work conditions in the New Economy are characterized as unstable and uncertain which was the justification for $\mathrm{H} 3$.

In summary, consistent with information drawn from the literature, these gender-matched results suggest in a convincing way that independent of time in the organization and independent of the associational groups, Supervisor, Peer or Team, the level of trust is higher in the Old Economy compared to that of the New Economy. 


\section{OVERALl SUMMARY AND CONCLUSION}

This study focused on gender differences in the levels of trust in the Brazilian New and Old Economies. The information garnered from the tests of $\mathrm{H} 1, \mathrm{H} 2$ and $\mathrm{H} 3$, suggest:

1) Overall $\mathrm{H} 1$ - that Brazilian males in the Old Economy would express more trust than their female counterparts - was supported. We see a strong male-trust effect for the Peer and Team associational groupings. For the Supervisor-Professional associational group, the results are suggestive. The implication is that the assumption that the traditional male imperative is pervasive and controlling in the Brazilian Old Economy is supported over all three associational groupings. These results fit with the recent work of Tanure (2006) and are interesting in relief given the social and economic revolutions in the 1980s and 1990s and the fact that the number of females as a percentage seems to be growing, as Table 2 suggests. This seems to speak for the strength of the male domination in the Brazilian Old Economy.

2) Regarding $\mathrm{H} 2$ - that due to the relative chaos in the New Economy there would be no gender patterns of trust - we observed, contrary to $\mathrm{H} 2$, that gender patterns do seem to exist within both the Professional and the Personal dimensions. In the Brazilian New Economy sector, we see that females seem to be more accepting of the authority of their managing supervisor and are therefore willing to place trust in that relationship. However this pattern breaks up at the peer level and changes to males expressing higher levels of trust at the team level. Here, too, extensive research is needed to investigate these patterns in the Brazilian ITC sector.

3) Regarding H3, which is supported, we observed that, controlling for gender, trust in the Brazilian Old Economy tested as uniformly greater than the trust expressed by those in the New Economy, independent of the time worked in the organization. Consistent with the work of Perry, DavisBlake and Kulik (1994), Burton-Jones (1999), Audretsch and Thurik (2001) and Argandona (2003), the dynamic nature of work in the New Economy seems to have created an environment where trust is less likely to develop.

\section{The Control Implications}

For the New Economy in Brazil over both the Professional/Reliance and the Personal/Disclosure dimensions, with respect to the authority of the Supervisors, we see that Brazilian women express more trust than do their male counterparts, whereas Brazilian men in the New Economy express more trust in their Team setting than do their female counterparts. Therefore, in these particular situations for the New Economy firms, one supposes that there will be relatively less need for monitoring for control. For example, when women are being supervised, one may expect that there will be less need for monitoring for opportunistic behavior than when managers are supervising men. The reverse is suggested for the team associational grouping. When males are involved with their team they express more trust than do their female counterparts and so seem to require less monitoring. This is of course based on the idea, as discussed above, that more trust is synonymous with less opportunistic behavior, and so less control is needed.

For the Brazilian Old Economy, the results are uniform for all three associational groups. Men express more trust than do their female counterparts. Therefore, given the higher level of trust expressed uniformly in the Old Economy by Brazilian men, one would expect less opportunist behavior for the males compared to the females. Perhaps such possible defection and opportunistic behavior expected for women has something to do with their marginalization in the Old Economy firms. This remains an important topic for future investigation. 
For H3, the matched time and gender analyses, the results are striking. The level of trust in the Brazilian Old Economy is higher compared to that found in the New Economy, controlling both for time in the organization and for gender. Therefore, there is a need to be more attentive to effect control through monitoring in the New Economy as the level of trust in the New Economy is uniformly lower that that in the Old Economy.

\section{The Outlook}

This research certainly raises some interesting questions, in particular with respect to $\mathrm{H} 2$ that overall is not supported. Much work is needed to understand the interactive nature of gender, institutional framework and the professional and personal dimensions in the dynamic Brazilian New Economy. Finally, these are the first such reported results from the Brazilian institutional framework and the first results that address the gender partition of trust in an institutional setting. Therefore, additional work is needed to see if our results are culturally specific. We are now in the process of designing a study for Germany and the United States to see whether these results have tapped into a human tendency or are culturally specific to Brazil.

\section{ACKNOWLEDGEMENTS}

We wish to thank Professor Mountcastle, Department of Anthropology SUNY: Plattsburgh, Plattsburgh, NY USA and two referees for their constructive comments, and Ms. Ellen Slack for her editorial assistance.

\section{REFERENCES}

Arabsheibani, G. R., Carneiro, F. G., \& Henley, A. (2003). Gender wage differentials in Brazil: trends over a turbulent era [Policy Research Working Paper Series No 3148]. The World Bank, Washington, DC, USA.

Arbache, J. S., \& Loureiro, P. R. A. (2005). Does gender discrimination exist? A natural experiment approach [Working Paper No 739208]. Catholic University of Brasília, Brasília, DF, Brasil.

Argandona, A. (2003). The new economy: ethical issues. Journal of Business Ethics, 44(1), 3-22.

Audretsch, D. B., \& Thurik, A. R. (2001). What's new about the new economy? Sources of growth in the managed and entrepreneurial economies. Industrial and Corporate Change Journal, 10(1), 267-315.

Axelrod, R. (1984). The evolution of cooperation. New York: Basic Books.

Bodnar, G. H., \& Hopwood, W. S. (2004). Accounting information systems. Upper Saddle River, NJ: Pearson/Prentice Hall.

Burke, C., Sims, S., Lazzara, E., \& Salas, E. (2007). Trust in leadership: a multi-level review and integration. Leadership Quarterly, 18(6), 606-632.

Burton-Jones, A. (1999). Knowledge capitalism - business work, and learning in the new economy. London: Oxford University Press.

Castells, M. (1996). The rise of the network society. The information age: economy, society and culture. Oxford: Blackwell Press. 
Conselho Nacional dos Direitos da Mulher. (2004). Contribuição da secretaria especial de políticas para as mulheres para as conferências estaduais - Documento base. Retrieved September 1, 2006, from http//www.sof.org.br/arquivos/doc/contr_secr_espec_polit_mulheres.doc

Cronbach, L., \& Meehl, P. (1955). Construct validity in psychological tests. Psychological Bulletin, 52(4), 281-302.

Fransman, M. (2002). Telecoms in the Internet Age - From boom to bust to...? New York: Oxford University Press.

Gillespie, N. (2003, August). Measuring trust in working relationships: the behavioral trust inventory. Proceedings of the Academy of Management Conference, Seattle, WA, USA.

Gillespie, N., \& Mann, L. (2004). Transformational leadership and shared values: the building blocks of trust. Journal of Managerial Psychology, 19(6), 588-607.

Gordon, G. G. (1991). Industry determinants of organizational culture. The Academy of Management Review, 16(2), 396-415.

Harmon, H. H. (1960). Modern factor analysis. Chicago: The University of Chicago Press.

International Labour Office. (1998). Structural and regulatory changes and globalization in postal and telecommunications services. The human resources dimension. Geneva: Author.

International Labour Office. (2001). World employment report 2001: life at work in the information economy. Geneva: Author.

International Labour Office. (2002). Reunión tripartita sobre empleo, empleabilidad e igualdad de oportunidades en los servicios de correos y telecomunicaciones. Genebra: Author.

Kreps, D. M. (1990). Corporate culture and economic theory. In E. A. James \& K. A. Shepsle (Eds.). Perspectives on positive political economy (pp. 90-143). Cambridge: Cambridge University Press.

Lewicki, R., Tomlinson, E., \& Gillespie, N. (2006). Models of interpersonal trust development: theoretical approaches, empirical evidence and future directions. Journal of Management, 32(6), 991-1022.

Lusk, E. J., Schmidt, G., \& Halperin, M. (2006). Recommendations for the development of a European venture capital regulatory corpus: lessons from the US. In G. Gregoriou, M. Kooli, \& R. Kraeussl (Eds.). Venture capital in Europe: the quantitative finance series. London: Elsevier Press.

Neumark, D., \& Reed, D. (2002). Employment relationships in the new economy [Paper $\mathrm{N}^{\circ}$ 8910]. National Bureau of Economic Research, Cambridge, MA.

Nunnally, J. (1978). Psychometric theory. New York: McGraw-Hill.

Perrons, D. (2002). Gendered divisions in the new economy: risks and opportunities. Geojournal, $56(4), 271-280$.

Perrons, D. Fagan, C., McDowell, L., Ray, K., \& Ward, K. (2006). Gender divisions and working time in the new economy: changing patters of work, care and public policy in Europe and North America. Cheltenham: Edward Elgar Publishing Limited.

Perry, E. L., Davis-Blake, A., \& Kulik, C. T. (1994). Explaining gender-based selection decisions: a synthesis of contextual and cognitive approaches. The Academy of Management Review, 19(4), 786-820. 
Press, A. L. (1991). Women watching television: gender, class, and generation in the American television experience. Philadelphia: University of Pennsylvania Press.

Ricketts, M. (2002). The economics of business enterprise. Cheltenham: Edward Elgar Publishing Limited.

Ring, P. S., \& Van de Ven, A. H. (1994). Developmental processes of cooperative interorganizational relationships. Academy of Management Review, 19(1), 90-118.

Ripperger, T. (1998). Ökonomik des vertauens. Tübingen: Mohr Siebeck Press.

Robbins, S. P. (2002). Organizational behavior - Concepts - Controversies - Applications. London: Prentice-Hall.

Standing, G. (1997). Globalisation, labour flexibility and insecurity: the era of market regulation. European Journal of Industrial Relations, 3(1), 7-37.

Tamhane, A. C., \& Dunlop, D. D. (2000). Statistics and data analysis. Upper Saddle River: Prentice Hall.

Tanure, B. (2005). Human resource management in Brazil. In M. M. Elvira \& A. Davila (Eds.). Managing human resources in Latin America: an agenda for international leaders (pp. 111128). London: Routledge Group Press.

Tanure, B. (2006). Human resource management in Brazil. In M. M. Elvira \& A. Davila (Eds.). Managing human resources in Latin America: an agenda for international leaders (pp. 111128), London: Routledge Group Press.

Williamson, O. E. (1975). Markets and hierarchies: analysis and antitrust implications. New York: The Free Press. 